\title{
Duas experiências de ensino remoto no curso de Licenciatura em Matemática da Unicamp
}

\author{
Leonardo Barichello[D \\ Marcelo Firer $^{1}$ (D) \\ Rita Santos Guimarães ${ }^{2}$ (1) \\ Letícia \\ Fernandes Soriani
}

\begin{abstract}
Resumo
Neste relato serão apresentadas duas disciplinas do curso de Licenciatura em Matemática da Unicamp oferecidas durante o primeiro semestre de 2020 e que tiveram suas atividades transferidas para o ensino remoto emergencial devido à pandemia. Os relatos sugerem como, apesar de bastante diferentes em termos de ementa, as duas disciplinas foram exitosas ao transpor suas atividades para o ensino remoto com uso de diversos recursos digitais. Além de descrever as dinâmicas usadas, nas duas disciplinas, apresentamos os princípios adotados e apontamos acertos e dificuldades na implementação. Ao mesmo tempo, sugerimos características que poderão ser incorporadas nas próximas edições das disciplinas, inclusive com o retorno das atividades presenciais.
\end{abstract}

Palavras-chave: ensino remoto emergencial; licenciatura em matemática; estágio; seminários

\begin{abstract}
In this paper, the authors present two courses offered to first year students in initial teacher education at Unicamp during the first semester of 2020, when all the activities at the university became online. Although the courses are quite different in terms their syllabuses, the authors show how they were both successfull by using a wide range of digital tools and resources. Beyond describing the dynamics adopted in both courses, the authors reflect on the principles adopted, some choices made and on what worked better. Finally, the authors suggest the characteristics that could remain as part of these courses even when the activities at the university return to normal.
\end{abstract}

Keywords: emergency online teaching; initial teacher education; internship; seminars

\section{Introdução}

\subsection{A reação da Unicamp à pandemia}

No dia 12 de março de 2020, quando o Brasil registrava poucas dezenas de infectados pelo coronavírus (Sars-CoV-2), em virtude da pandemia de Covid-19, a Unicamp suspendeu as atividades

\footnotetext{
${ }^{1}$ Parcialmente apoiado pelo CNPq, bolsa PQ 304046/2017-5. O autor gostaria de agradecer os tutores e monitores da disciplina MA105, pelo enorme comprometimento com os alunos e com a matemática.
}

${ }^{2}$ Apoiada por FAPESP, processo 2019/17135-2. 
acadêmicas presenciais pelo período de 30 dias, estabelecendo que essas poderiam "ser substituídas por atividades não presenciais, realizadas sob orientação docente" (Resolução GR-024/2020). Quase que concomitantemente, dia 16 de março, foi criado um programa emergencial para os cursos e disciplinas de Graduação e Pós-Graduação, prevendo a elaboração de propostas a serem encaminhadas à administração central no prazo de uma semana. Finalmente, dia 24 de março (Resolução GR-035/2020), é estabelecido que a suspensão das atividades presenciais fica prorrogada por prazo indeterminado, que os calendários de Graduação e Pós-Graduação deverão ser adaptados, e que as disciplinas "com o emprego de estratégias de aprendizagem não presenciais deverão ter as atividades iniciadas até o dia 15 de abril de 2020".

A administração central da Unicamp ofereceu apoio a adaptação das atividades docentes à distância, por meio dos recursos oferecidos pelo Grupo Gestor de Tecnologias Educacionais (principalmente os recursos Google Meet, Google Sala de Aula e Moodle) e um amplo apoio ao ensino remoto oferecido pelo Espaço de Apoio ao Ensino e Aprendizagem (EA2), que organizou uma página com ferramentas, tutoriais e materiais de apoio a atividades acadêmicas com uso de recursos digitais. Também nas unidades de ensino houve forte mobilização de docentes e ampla troca de experiências, por meio de tutoriais, trocas de mensagens e encontros virtuais. Além disso, a partir de 6 de abril, iniciou-se o empréstimo de computadores a estudantes e acordos para planos de internet de baixo custo.

Na prática, embora muitas disciplinas tenham iniciado sua adaptação ao ensino remoto já em março, até dia 15 de abril praticamente todas as disciplinas de Graduação e Pós-Graduação foram retomadas na Unicamp (exceções feitas a disciplinas que demandam presença física em laboratórios e estágios). No Instituto de Matemática, Estatística e Computação Científica (Imecc), todas as disciplinas foram adaptadas para o ensino remoto. Os programas adotados em cada uma delas foram disponibilizados na página dedicada do Imecc.

É importante destacar que o corpo docente engajou-se de modo muito intenso nas atividades de ensino durante esse período de isolamento social. Em encontro para socialização de experiências feito pelo Imecc em agosto, no final do semestre, os depoimentos de docentes foram consensuais na percepção de que houve de fato um bom aproveitamento dos estudantes em termos de aprendizagem, a despeito de dificuldades e dúvidas no que se refere a avaliações e provas a distância. Vale comentar que a Comissão Central de Graduação permitiu que os docentes optassem por atribuir apenas o conceito de suficiente ou insuficiente, em vez das notas tradicionais (de 0 a 10). No Imecc, a maioria dos docentes sentiu-se confortável para avaliar seus estudantes atribuindo notas tradicionais e apenas as chamadas disciplinas coordenadas (disciplinas com mais de 10 turmas distintas) e três disciplinas isoladas optaram pelos conceitos suficiente ou insuficiente.

\subsection{Objetivo}

O objetivo deste artigo é apresentar as atividades que foram desenvolvidas em duas disciplinas do curso de Licenciatura em Matemática noturno da Unicamp durante o período de aulas remotas em caráter emergencial. As disciplinas são MA104 - Seminários sobre Ensino de Matemática e MA105 - Matemática Elementar, disciplinas do primeiro semestre letivo, destinadas a ingressantes do curso.

Além de atenderem calouros do curso de licenciatura, as duas disciplinas, com características muito diferentes entre si, tiveram uma característica comum neste ano de 2020: ambas migraram muito rápido para ensino remoto emergencial, neste excepcional primeiro semestre de 2020. 
No caso da disciplina Seminários sobre Ensino de Matemática, o foco do relato será sobre como as diferentes ferramentas disponíveis foram utilizadas para materializar atividades em formatos muito diversificados ao longo do semestre.

No caso de Matemática Elementar será salientado como as atividades de uma disciplina de natureza similar a um estágio foram transpostas para e desenvolvidas no contexto digital.

\title{
1.3. Princípio norteador para as duas disciplinas
}

Apesar de não fazer parte dos objetivos deste texto realizar discussões e aprofundamentos teóricos acerca da formação inicial de professores e a natureza do seu conhecimento, parece-nos pertinente apresentar alguns princípios que nortearam as atividades propostas nas duas disciplinas.

Desde a década de 1980, com as propostas fundacionais de Shullman [9], desenvolveram-se inúmeros estudos sobre o conhecimento de professores de matemática. Esses trabalhos convergem no sentido de identificar o conhecimento do professor de matemática como um conhecimento específico, diferente do conhecimento do matemático e do pedagogo. Conquanto ainda haja questões de natureza prática e teórica em aberto no que diz respeito a como medir, desenvolver e caracterizar tal conhecimento, alguns autores já identificam consensos que emergem desse campo de investigação.

\begin{abstract}
A partir de décadas de pesquisa, elencamos aqui algumas conclusões emergentes e inter-relacionadas: Ensinar a professores tópicos convencionais de matemática além de um nível fundamental não impacta o conhecimento desses professores de forma que afete o ensino e aprendizagem em sala de aula; Criar oportunidades para aprender matemática de forma entrelaçada com contextos de ensino aumenta o conhecimento específico dos professores; O foco do conteúdo, da atividade e da pedagogia para ensinar tal conhecimento exige atenção à manutenção de um equilíbrio entre o conteúdo e aspectos de ensino, sem que se enfatize exclusivamente nenhum dos dois. (Hoover et al, 2016, p. 12 - tradução nossa)
\end{abstract}

Desse argumento, extraímos um grande princípio que informou as atividades desenvolvidas nas duas disciplinas relatadas neste texto: a importância de discutir o conteúdo matemático interconectado com aspectos de ensino e aprendizagem do próprio conteúdo e não com ênfase apenas em conteúdos matemáticos por si só. Embora haja incertezas e discordâncias sobre como manter essa relação de maneira concreta em uma disciplina de formação de professores, esse princípio coloca um horizonte amplo, mas esclarecedor, que norteou as atividades relatadas neste artigo.

Vale a pena destacar que tais disciplinas foram criadas para um novo currículo implementado na Unicamp a partir de 2015 e ainda estão em processo de consolidação de sua proposta didática. Como veremos mais adiante, acreditamos que a experiência desse período de ensino remoto pode contribuir para o desenvolvimento futuro das disciplinas.

\section{Disciplina Seminários Sobre o Ensino de Matemática}

A disciplina Seminários Sobre o Ensino de Matemática - MA104 corresponde a dois créditos em um total de 214 necessários para se formar no curso, sendo que, em geral, um licenciando em Matemática cursa em torno de 20 créditos por semestre. Esta é uma disciplina obrigatória oferecida 
aos calouros (primeiro semestre) e é uma das poucas disciplinas do curso cuja avaliação é apenas por frequência - dentre as outras cinco do currículo que seguem o mesmo critério de aprovação, três são obrigatórias voltadas à participação em atividades de enriquecimento do universo cultural matemático e duas são disciplinas eletivas de iniciação científica.

Um dos propósitos pragmáticos desse critério de avaliação por frequência é proporcionar oportunidade aos estudantes que ingressam em chamadas avançadas e preferem trancar outras disciplinas, mas não podem trancar todas devido ao regimento de graduação da universidade.

A ementa de MA104 é: "Palestras sobre o ensino de matemática no ensino fundamental e médio, visando o direcionamento da formação acadêmica dos alunos ingressantes". Ou seja, apesar de existir a figura do professor responsável, e este ministrar alguns dos encontros, a ementa é bastante flexível e é comum ter como palestrantes outros docentes do instituto, professores de escola básica e outros profissionais ligados à área. Essa é a única disciplina de caráter eminentemente pedagógico no primeiro semestre do curso.

Após dois encontros presenciais, a Unicamp suspendeu as atividades no campus e a migração para o modo remoto foi iniciada.

Algumas adaptações foram necessárias devido às novas condições e vários palestrantes já programados para apresentar na disciplina cancelaram a participação. Mesmo com a possibilidade de estender convites para palestrantes em diferentes localidades, havia o incentivo de não restringir o ensino remoto emergencial a situações síncronas, o que poderia tornar a disciplina um "assista às seguintes palestras". Com o intuito de proporcionar experiências mais interessantes aos estudantes, optou-se por abandonar o formato de palestras e adotar atividades semanais independentes e variadas em termos de conteúdo e formato.

A adoção de atividades distribuídas na semana foi outra alteração adotada. Os encontros semanais síncronos de $2 \mathrm{~h}$ ainda aconteciam, mas a atividade a ser realizada na semana não dependia desse momento. Abaixo descrevemos brevemente o tópico e o objetivo geral de todos os encontros, na ordem em que foram realizados.

1. Cálculo com horas: Discutir diferentes resoluções de estudantes fictícios para um problema que envolvia o cálculo com horas e minutos no sentido de desenvolver o conhecimento interpretativo dos participantes [3];

2. Quadrado de expressões (2.1): Apresentar e discutir, sob o ponto de vista matemático e pedagógico as potencialidades de uma atividade de natureza exploratória [1];

3. Onde vai a vírgula? (2.2): Discutir diferentes explicações em vídeo para a etapa de colocar a vírgula durante a realização de uma divisão de números racionais;

4. Revista do Professor de Matemática: Realizar a leitura crítica e elaborar uma resenha curta de um texto desse periódico dentre um conjunto de textos pré-selecionados pelos professores responsáveis (por suas relações com as demais disciplinas em curso no semestre);

5. Multiplicação de matrizes: Participar de uma atividade de julgamento comparado [6] em torno do tópico multiplicação de matrizes, na qual cada participante deveria submeter uma resposta e realizar o julgamento comparado de algumas respostas dadas pelos colegas;

6. Divisão de frações: Resolução e discussão de questões no estilo utilizado pelo projeto Learning Mathematics for Teaching ([8]), ou seja, questões objetivas que enfatizam a compreensão dos significados envolvidos na divisão de frações; 
7. O que fazer com o Geogebra (2.3): Apresentação e discussão de atividades em formatos variados com uso do software Geogebra;

8. Pensamento Computacional: Discussão de atividades que desenvolvem o pensamento computacional dentro das tendências sugeridas pela Base Nacional Curricular Comum (BNCC);

9. Blocos de demonstração: Realização de uma série de atividades usando blocos encaixáveis para o ensino de demonstrações matemáticas. Essa série de atividades faz parte de uma pesquisa de doutorado em andamento [10];

10. Criação de aula digital com vídeo: Apresentação e uso da plataforma TED-Ed Lessons para montagem de aulas a partir de vídeos.

Para cada um desses tópicos, ao invés de compor as atividades de cada semana por um único item relativamente longo, como uma vídeoaula de longa duração, palestra ou lista de exercícios, decidimos utilizar vários itens de curta duração, viabilizando assim um uso mais intenso do aspecto multimídia do ambiente digital. O uso de itens de curta duração permitiu aos professores responsáveis combinar elementos como vídeos curtos, leituras, questões discursivas, questões objetivas, dentre outros recursos disponíveis na internet, para que os estudantes explorassem o tema de cada semana antes do encontro síncrono e estivessem prontos para participação ativa na discussão.

Os encontros síncronos foram usados como momentos de aprofundar a discussão do tópico da semana. A participação era contabilizada pela realização das atividades.

Essa combinação de recursos multimídia e a natureza das discussões propostas nos encontros síncronos serão discutidos em detalhes nas seções a seguir para três semanas da disciplina.

Como conhecer detalhes tanto do conteúdo quanto da forma são importantes para que se compreenda como as atividades foram desenvolvidas na disciplina, criamos uma página que imita a apresentação das atividades no Google Sala de Aula para cada uma das seções a seguir. Assim, é possível navegar e verificar como as atividades foram concretamente montadas. Obviamente, alguns botões não são funcionais, mas buscamos incluir todos os itens necessários para que o conteúdo e interação esperada em cada semana fiquem claros.

\subsection{Quadrado de expressões}

Um quadrado de expressões é um arranjo, como o ilustrado na Figura 1, no qual quatro expressões algébricas são colocadas de modo a determinar seis equações. A questão direta a ser feita a partir desse arranjo é: quais são as seis soluções? Entretanto, a questão inversa é muito mais interessante do ponto de vista matemático: dado um conjunto de seis soluções, encontre um quadrado de expressões cujas soluções sejam essas.

Esse tipo de atividade é caracterizada em [1] como um "estudos matemático", em analogia com o conceito de estudo musical. Isso significa que a atividade promove a fluência com um certo procedimento (resolver equações, neste caso) ao mesmo tempo que tem um caráter matematicamente instigante.

O objetivo ao propormos essa atividade na disciplina era duplo. Por um lado, proporcionar aos estudantes a experiência de resolver uma atividade com essa característica. Por outro, discutir essas características e suas potencialidades como futuros professores de matemática. 


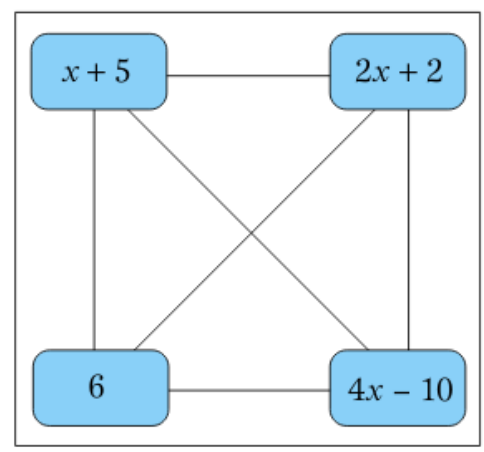

Figura 1: Exemplo de um quadrado de expressões.

No ambiente online, a atividade foi estruturada como itens sequenciais e um encontro síncrono, como descrito abaixo e como pode ser visualizado em https://www.ime.unicamp.br/ barichello/ pmo/classroom1.html.

- Um vídeo de cerca de 5 minutos de duração apresentando o conceito de "quadrado de expressões";

- Uma questão objetiva, na forma de múltipla escolha, que pedia a resolução de um quadrado de expressões dado;

- Uma questão mais aberta, a ser entregue como um arquivo com o processo de resolução e não apenas a solução final, que pedia um quadrado de expressões a partir de um conjunto de soluções dado;

- Um vídeo de cerca de 5 minutos de duração discutindo alguns aspectos de natureza mais pedagógica;

- Sugestão de material extra, voltado para professores, discutindo a ideia de "estudos matemático" com maior profundidade e recomendação de um site sobre o tópico;

- Uma atividade coletiva, concretizada através de um arquivo online compartilhado, em que os estudantes foram solicitados a criar e compartilhar quadrados de expressões com "conjunto de soluções interessantes";

- Um encontro síncrono de 2 horas de duração para discussão de quadrados de expressão sob o ponto de vista matemático-pedagógico (não disponibilizado para preservar a privacidade dos estudantes);

- Um texto com comentários finais com o intuito de propiciar um encerramento no tema com base nas respostas dadas às questões e às discussões que despertaram maior interesse durante o encontro síncrono.

Um aspecto que nos chamou a atenção foi o efeito da variedade dos itens utilizados na participação dos estudantes. Por um lado, o uso de itens fechados, como a questão objetiva, servia como indicativo de uma participação mínima de todos os estudantes. Por outro lado, itens como a atividade coletiva criaram a possibilidade de um engajamento adicional para alguns estudantes. 
Por fim, podemos afirmar que o ambiente que se instaurou durante o encontro síncrono foi muito produtivo, uma vez que as etapas iniciais, de apresentação de conteúdos e conceitos, já tinham sido realizadas pelos estudantes ao resolverem as atividades propostas. Isso permitiu que o encontro fosse concentrado em discussões entre os presentes, aproximando-se do que os adeptos de cenários de sala de aula invertida sugerem como mais adequado para os momentos coletivos. Após esclarecer algumas dúvidas, fizemos a apresentação de alguns casos selecionados entre os diversos exemplos postados na atividade coletiva. Durante essa apresentação, com incentivo dos professores, os estudantes foram capazes de formular conjecturas sobre a relação entre os coeficientes das expressões e as soluções das equações. Apesar de não ter sido possível atingir resultados de forma rigorosa, os estudantes puderam vivenciar momentos de investigação onde era necessário ouvir e interpretar as hipóteses de um colega, fazer testes e verificações, avaliar observações e refinar a hipótese inicial.

\subsection{Onde vai a vírgula?}

Nesta atividade, o objetivo era promover uma discussão que contribuísse para o desenvolvimento do conhecimento interpretativo dos estudantes como futuros professores de matemática, ou seja, o tipo de conhecimento necessário para interpretar e reagir adequadamente a situações não planejadas que podem emergir em uma sala de aula durante atividades envolvendo conteúdos matemáticos $([3])$.

Nesse caso, propusemos uma discussão sobre as justificativas, explícitas ou não, para um procedimento relacionado ao algoritmo da divisão: o posicionamento da vírgula no quociente. Para fomentar essa discussão, criamos os itens descritos abaixo e acessíveis em https://www.ime.unicamp. br/ barichello/pmo/classroom2.html.

- Um vídeo de cerca de 5 minutos de duração apresentando o objetivo da atividade;

- Uma questão objetiva, na forma de múltipla escolha, que pedia a resolução de algumas divisões cujo quociente teria parte decimal;

- Dois vídeos da Khan Academy, com duração de menos de 10 minutos cada, nos quais os autores realizavam a mesma divisão com quociente decimal descrevendo o processo de colocação da vírgula de maneiras diferentes;

- Uma questão discursiva, que pedia aos estudantes que resolvessem uma divisão com quociente decimal e complementassem essa resolução com comentários que explicassem os passos realizados como se estivessem explicando para alguém com dúvida sobre o procedimento;

- Um vídeo de menos de 10 minutos no qual a professora justificava explicitamente a colocação da vírgula no quociente de uma divisão;

- Um questão discursiva que pedia aos estudantes que explicassem uma nova divisão usando o mesmo tipo de argumentação apresentada no vídeo anterior;

- Um questão discursiva e opcional que pedia aos estudantes que criassem um novo exemplo de divisão que fosse particularmente bom para promover a discussão sobre a colocação da vírgula em uma turma de estudantes que estivesse aprendendo esse conteúdo. As respostas a essa questão ficaram disponíveis para consulta de outros colegas; 
- Um encontro síncrono no qual apresentamos algumas das respostas dadas pelos estudantes e pedimos a eles que elaborassem as suas justificativas, que nem sempre haviam ficado claras nas suas respostas.

- Um texto com comentários finais com o intuito de dar um encerramento no tema, tendo sido solicitado aos estudantes que revissem suas entregas considerando alguns erros comuns que os professores encontraram ao avaliar as entregas anteriores.

Mais uma vez, salientamos o uso de itens em diferentes formatos, mas agora buscando promover discussões mais explicitamente focadas no aspecto pedagógico do conteúdo. Durante a discussão no encontro síncrono, os estudantes ficaram bastante intrigados sobre as sutilezas envolvidas na explicação, e como um procedimento da matemática elementar podia ser discutido com tanta profundidade.

Nessa semana, a inexperiência dos estudantes em lidar com aspectos pedagógicos de um conteúdo matemático ficou ainda mais evidente. Quase a totalidade das explicações da primeira questão discursiva sobre o posicionamento da vírgula foram verbalizações do procedimento sem nenhuma tentativa de justificá-lo. Mesmo nas resoluções da questão discursiva, após assistirem uma sugestão de como poderia ser uma justificativa, diversos estudantes ainda não produziram explicações para além da descrição do procedimento.

\subsection{O que fazer com o Geogebra}

As duas atividades anteriores, apesar de terem objetivos diferentes e serem ambas compostas por muitos itens em formatos variados, ainda guardam uma certa semelhança na estrutura: algumas questões objetivas para estabelecer o que pode ser visto como um conhecimento basal para participar das discussões, vídeos situando a atividade e seus principais conceitos e questões discursivas que exigiam mais reflexão.

A terceira atividade que gostaríamos de descrever neste artigo teve um formato diferente. Nesse caso, o objetivo era apresentar o software Geogebra para os estudantes, mas não no sentido instrumental, ensinando-os como utilizar certos recursos, e sim no sentido de mostrar-lhes que o software pode ser utilizado como ferramenta pedagógica de maneiras diferentes.

Basicamente, a atividade foi composta por três itens e um encontro síncrono, como pode ser visto em https://www.ime.unicamp.br/ barichello/pmo/classroom3.html. Cada um desses três itens fazia um uso diferente de uma construção no Geogebra.

No primeiro deles, uma construção pronta era dada, e os estudantes podiam apenas explorar alguns elementos livres para encontrar a resposta de um problema colocado. No segundo deles, foi dado um problema e um roteiro textual para criação de uma construção que poderia ser usada para encontrar a resposta. Por fim, no terceiro item, apenas o problema era posto e ficava a cargo dos estudantes criar uma construção que lhes ajudasse na resolução.

Em cada um dos itens anteriores, a devolutiva esperada era diferente. No primeiro, utilizamos apenas uma questão objetiva; no segundo, os estudantes deveriam realizar a construção para responder a uma questão de resposta curta (coordenadas de um ponto); e no terceiro a devolutiva deveria ser a construção realizada contendo uma indicação da resposta ao problema.

O encontro síncrono foi dividido entre os três problemas, e a maior parte do tempo foi utilizado na discussão da resolução de cada um deles. Todos os problemas eram de geometria e os estudantes 
não se mostraram familiarizados com todos os conceitos envolvidos, o que fez com que as discussões em relação aos aspectos pedagógicos das atividades fossem reduzidas.

\subsection{Comentários finais sobre MA104}

O que queremos salientar neste relato é a variação no tipo de conteúdo e no tipo de interação obtidos na montagem das atividades semanais, sendo que todos os itens foram realizados com recursos nativos no ambiente virtual de aprendizagem ou através de ferramentas digitais amplamente conhecidas.

Vale ressaltar que, após cada data de entrega, a gravação do encontro síncrono era disponibilizada. Além disso, para todas as atividades, os professores avaliavam as entregas dos estudantes e montavam um material de finalização da semana. Para a atividade Quadrado de Expressões, foram disponibilizados comentários gerais e um arquivo com exemplo de soluções, incluindo o passo-apasso para algumas delas. Para a atividade Onde vai a vírgula?, os professores elaboraram um texto curto (duas páginas) comentando sobre as principais deficiências de algumas explicações, e solicitou-se aos estudantes a relerem suas entregas após a leitura dos nossos comentários. Por fim, após a atividade $O$ que fazer com o Geogebra fornecemos leitura complementares sobre cada um dos problemas propostos.

Tivemos pouco retorno a respeito desses materiais de finalização das atividades e não temos evidência de que elas tenham de fato engajado os estudantes para além de alguns comentários isolados.

Do ponto de vista da variedade dos tipos de itens usados para montar cada atividade, consideramos a opção exitosa em dois aspectos.

Primeiro, possibilitou o uso de diferentes recursos digitais, permitindo que utilizássemos ferramentas que se adequavam ao que gostaríamos de explorar em cada atividade.

Segundo, um efeito que não antecipamos mas observamos em várias das atividades propostas, foi a potencialização de diferentes níveis de engajamento para além do mínimo esperado, pois alguns dos formatos utilizados permitiram naturalmente maior ou menor participação de acordo com o interesse dos estudantes. Além disso, acreditamos que a grande variação no que se esperava que fosse entregue (indo de resoluções de questões puramente matemáticas até reflexões pedagógicas, feitas a mão ou com suporte de softwares específicos) acabou por fazer com que todo estudante encontrasse alguma tarefa que lhe despertasse maior interesse, gerando um engajamento maior.

No que diz respeito aos princípios norteadores que apresentamos na seção 1.3, sentimos o quão desafiador é manter o balanço entre o foco na matemática e no ensino ao longo das atividades, como apontado por [5].

Durante o encontro síncrono da atividade Quadrado de Expressões, o foco acabou ficando quase que exclusivamente no aspecto matemático, uma vez que os estudantes trouxeram diversas conjecturas sobre o problema e a discussão pautou-se em formular tais conjecturas, testá-las e identificar caminhos para eventuais demonstrações. Já durante o encontro síncrono da atividade Onde vai a vírgula?, o foco foi maior em aspectos pedagógicos do conteúdo, pois os estudantes demonstraram grande interesse em compreender as diferentes justificativas, dadas de forma explícita ou não, pelos autores dos vídeos analisados. Por fim, no encontro síncrono da atividade $O$ que fazer com o Geogebra, mais uma vez a ênfase recaiu sobre a resolução matemática dos problemas e não na discussão sobre as diferentes potencialidades pedagógicas de cada um dos usos exemplificados. 
Nossa percepção é de que o balanço entre o aspecto matemático e o pedagógico de conteúdo é muito influenciado pela escolha das atividades, mas também seria beneficiado por uma familiaridade maior dos futuros professores em formação com esse "modo de pensar". No caso que relatamos, esses futuros professores estavam no seu primeiro semestre de formação inicial, mas essa observação sugere a importância de incluir mais disciplinas com foco no conhecimento pedagógico de conteúdo nos currículos dos curso de Licenciatura em Matemática.

\section{Matemática Elementar e Ensino e Prática de Matemática}

A necessidade de criar disciplinas que auxiliem os estudantes do curso de Licenciatura em Matemática noturno da Unicamp em suas dificuldades com conteúdos matemáticos do Ensino Médio e que os apoie em sua inserção no ambiente universitário foi detectada ainda na década de 90. O currículo de 1998 postergou a disciplina de Cálculo Diferencial e Integral para o segundo semestre e inseriu no primeiro semestre uma disciplina chamada Matemática Básica (MA109), que teria caráter remedial, abordando conteúdos típicos do Ensino Médio. Também criou 6 disciplinas, denominadas Laboratório de Matemática que tinham como propósito acompanhar e apoiar as disciplinas de conteúdo matemático do semestre vigente. Esse foi um movimento em direção necessária, mas que enfrentou uma série de limitações em seu impacto, dentre as quais a impossibilidade de determinar quais seriam as disciplinas efetivamente acompanhadas, haja vista que a progressão dos estudantes em um sistema de créditos não seriado é não homogênea.

Tal mudança teve impacto significativo na progressão dos estudantes, aumentando significativamente o número de formandos. A experiência, foi considerada bem-sucedida, e a disciplina Matemática Básica foi substituída pela disciplina Matemática Elementar (MA105), com o dobro de carga horária (8 horas de atividade em sala por semana).

Mais do que dobrar o número de horas de atividade, a mudança mais significativa foi a criação da disciplina Currículo e Didática da Matemática: Teoria e Prática (MA705), uma disciplina destinada a estudantes do último período letivo ( $9^{\circ}$ semestre), que em grande parte acompanha a disciplina de Matemática Elementar.

A disciplina Currículo e Didática da Matemática tem um enfoque duplo: contribuir com a formação docente dos estudantes da disciplina, próximos de se licenciar como professores de matemática, ao mesmo tempo que apoia os calouros, exercendo um "sistema de tutoria com os alunos da disciplina MA105 - Matemática Elementar"3. A disciplina tem seis horas semanais de atividade em sala, sendo quatro dedicadas à tutoria dos calouros (presencial, nas mesmas salas de aula) e duas devotadas à apresentação de atividades planejadas e reflexão sobre o uso das mesmas. Em um certo sentido, essa disciplina pode ser considerada uma espécie de estágio interno, que permite abordar de modo organizado, sistemático e reflexivo diversos aspectos atinentes à prática de professores de matemática ${ }^{4}$.

Oferecida pela primeira vez como disciplina eletiva para grupo pequeno de estudantes em 2017, a disciplina MA705 foi oferecida como obrigatória em 2019, contando com um número significativo de matriculados. Em 2020, em sua segunda edição, durante a pandemia, o aspecto de tutoria

\footnotetext{
${ }^{3}$ Programa oficial da disciplina, página 134 do Projeto Pedagógico dos Cursos de Graduação em Matemática, disponível em https://www.ime.unicamp.br/sites/default/files/inline/349/ppp2015.pdf.

${ }^{4}$ Do programa oficial da disciplina constam, dentre outros, os seguintes tópicos: conhecimento de currículo de matemática do Ensino Básico, planejamento de disciplina, preparação de aula, utilização de acessórios didáticos, preparação de listas de exercícios, avaliação, dificuldades de aprendizagem dos alunos e orientação para resolução de problemas.
} 
previsto no programa mostrou um vigor destacado, tanto no que se refere ao apoio aos tutorados (calouros) como na formação docente dos tutores (veteranos próximos da conclusão do curso).

Essa relação entre calouros e veteranos, ancorada no currículo e na sala de aula, e as muitas peculiaridades de seu oferecimento de modo remoto, tem um papel central neste relato que, em princípio, foca na disciplina Matemática Elementar. Para fins de organização do texto, a partir desse ponto usaremos calouros para nos referir os estudantes matriculados em MA105 e tutores para nos referirmos aos estudantes matriculados em MA705 (prestes a finalizarem o curso)

\subsection{Estrutura prevista para a disciplina Matemática Elementar}

A disciplina Matemática Elementar (MA105) estava planejada para duas sessões semanais, cada uma com quatro horas/aula, contando com cerca de 80 estudantes: os 70 ingressantes do curso de licenciatura e alguns estudantes cursando a disciplina fora da grade proposta.

A primeira metade de cada sessão estava planejada para ser uma aula expositiva do docente responsável, abordando os conteúdos previstos na ementa. Na transição entre as duas metades estavam previstas breves apresentações dos próprios calouros de "coisas legais" de matemática. A proposta era que, desde o primeiro semestre, os estudantes tivessem contato com fontes diversificadas de conteúdos, aumentando seu repertório de referências. A segunda metade de cada sessão previa a participação dos alunos de MA705, atuando como tutores da turma. O tempo seria dividido entre resolução de exercícios em grupos (acompanhados pelos tutores), uma resolução comentada dos exercícios da aula anterior a ser feita por duplas de tutores e um breve tempo para trabalho individual em exercícios.

As listas de exercícios em grupo eram entregues a cada aula e corrigidas pelos tutores, que assim poderiam fazer uma resolução comentando as principais dificuldades e estratégias adotadas pelos calouros.

Já as aulas presenciais de MA705 (exclusivamente com os tutores), de duas horas semanais, seriam dedicadas à discussão sobre as apresentações feitas pelos tutores ao longo da semana (comentários e discussão de exercícios em grupo da aula anterior), com algum tempo para discutirmos questões genéricas (de caráter organizacional ou didático-pedagógico).

\subsection{Adaptação da disciplina para ensino remoto}

O cancelamento das atividades presencias na Unicamp, a partir de 16 de março, causou séria preocupação referente ao engajamento e evasão, por se tratar da principal disciplina dos calouros, que tiveram quase nenhum contato com o estimulante ambiente universitário. A aula do dia 16 de março foi cancelada, no dia 17 foi discutida uma proposta de readequação com a turma dos tutores, no dia 18 foi feita uma aula remota com a turma de MA105 na qual foi apresentada a proposta de reformulação da disciplina e já na semana seguinte foram retomadas as atividades.

A seguir, apresentamos brevemente a proposta feita para a retomada das atividades de modo remoto.

Antes de tudo, a turma foi dividida em pequenos grupos (3 ou 4 calouros) e a cada grupo foi designado um tutor.

Para cada aula, o professor gravou um vídeo (no total foram gravados 24 vídeos, com duração entre 80 e 125 minutos) que deveriam ser assistidos pelos calouros antes da aula síncrona, realizada pelo 
Google Meet. Além disso, era preparada uma lista de exercícios que deveria ser entregue em um prazo de quatro dias.

Aos tutores caberia corrigir e comentar as listas resolvidas entregues e propor exercícios adicionais, de acordo com a necessidade detectada de cada um. Para cada uma das listas de exercícios foi designada uma dupla de tutores, que deveriam redigir soluções dos exercícios, comentando as dificuldades, explicando e enriquecendo os conteúdos.

Os estudantes de MA105 foram estimulados a ler os comentários e re-submeter seus exercícios quando necessário, com prazo a ser estipulado por seu tutor.

Os tutores foram estimulados a acompanhar e incentivar os calouros do seu grupo, não apenas nos aspectos de conteúdos matemáticos, mas na adaptação ao ensino universitário e na apresentação da Unicamp como um todo.

A avaliação da disciplina seria baseada em três provas, nas listas de exercícios e na entrega (sem correção) dos exercícios adicionais.

\subsubsection{Recursos computacionais e de comunicação remota utilizados}

Considerando que todas as atividades foram realizadas sem presença física, achamos pertinente relatar sobre os recursos de comunicação remota utilizados.

A gestão da sala de aula foi feita pelo Google Sala de Aula e as aulas síncronas utilizando o Google Meet (as aulas eram gravadas e depois disponibilizadas aos alunos, no material da semana). Os tutores criaram pequenos grupos no WhatsApp para se comunicar com sua pequena turma de calouros e também foram criados dois grupos de WhatsApp com todos os tutores e monitores da disciplina, um com a participação do docente responsável, outro exclusivo a tutores e monitores ${ }^{5}$.

As aulas foram gravadas em um tablet, utilizando o aplicativo Explain Every Thing. As provas foram corrigidas utilizando o software Gradescope (permite comentários, ajuste de grade de correção e organização por perguntas) e Kami (que em sua versão ampla, liberada por curto período, permite comentários em LaTeX e comentários gravados). Considerando todos os alunos como futuros professores de Educação Básica, durante as aulas síncronas e em alguns vídeos gravados foram utilizados recursos variados, com o intuito de apresentar aos alunos fontes diversas que estão disponíveis a professores de matemática ${ }^{6}$.

\subsection{Tutoria}

Com a mudança para as aulas remotas, foram necessárias alterações acerca do planejamento das disciplinas. Uma delas foi com relação à tutoria, que, não podendo se realizar em sala de aula, foi ampliada para os mais diversos meios de comunicação remota. A seguir, são apresentadas tais adaptações, bem como sua influência no processo de formação de todos os alunos envolvidos com o andamento da disciplina (perceptíveis, em sua maioria, devido à proximidade estabelecida entre tutores e calouros).

\footnotetext{
${ }^{5} \mathrm{~A}$ disciplina contou com dois monitores, alunos de graduação, que além de manterem um horário semanal de atendimento, gerenciaram e organizaram todo o material na sala de aula virtual.

${ }^{6}$ Os recursos apresentados foram Kahoot, Geogebra, Matrix Calculator e formulários on-line, além de importantes acervos como Portal da Matemática, M3, Numberphile, 3Blue1Brown e Revista do Professor de Matemática.
} 


\begin{tabular}{|c|c|c|c|}
\hline Atividade & $\begin{array}{c}\text { Alunos de MA105 } \\
\text { (calouros) }\end{array}$ & Tutores & Docente \\
\hline Aulas gravadas & Assistem & $\begin{array}{c}\text { Assistem } \\
\text { eventualmente }\end{array}$ & $\begin{array}{c}\text { Produz } \\
\text { por semana }\end{array}$ \\
\hline Aulas síncronas & Participam & Coordena \\
\hline Listas de Exercícios & Resolvem & $\begin{array}{c}\text { Elaboram soluções comentadas; } \\
\text { Corrigem do seu grupo } \\
\text { de tutoria }\end{array}$ & $\begin{array}{c}\text { Elabora } \\
2 \text { listas semanais }\end{array}$ \\
\hline $\begin{array}{c}\text { Contato individual } \\
\text { com alunos de MA105 }\end{array}$ & $\begin{array}{c}\text { Semanal } \\
\text { (via Google Meet e } \\
\text { Sala de Aula, WhatsApp) }\end{array}$ & Eventual \\
\hline
\end{tabular}

Tabela 1: Estrutura e atribuições básicas em uma semana típica de aula.

\subsubsection{Descrição das atividades e organização}

Como já mencionado na seção 3.2, a disciplina manteve sua proposta original, com a formação de pequenos grupos (três ou quatro ingressantes) tutorados por um veterano, chamados grupos de tutoria. Nesta seção descreveremos com mais detalhes a organização efetiva da disciplina, assim como os ajustes feitos ao longo do semestre.

Um primeiro contato dos tutores com o seu grupo deu-se, de modo geral, por meio de mensagens de e-mail, com troca de contatos de celular para que se reunissem através de aplicativos de comunicação, o que se mostrou bastante importante. Além de ferramenta essencial para a comunicação entre os grupos de tutoria, a existência de um grupo sem a presença do docente responsável resultou em eventuais discussões sobre as listas e versões preliminares das resoluções comentadas, permitindo que tutores dedicassem um tempo maior às dúvidas de seus tutorados.

O processo de condução da tutoria deu-se de forma autônoma por parte dos tutores. As três principais abordagens foram:

- Concentração das dúvidas apenas nos grupos de WhatsApp;

- Encontros síncronos entre tutores e seu grupo de calouros.

- Mescla dos dois itens anteriores.

O contato frequente entre tutores e calouros, ponto-chave para o andamento da disciplinas, mostrouse efetivo em quase todos os grupos.

As questões que na proposta original deveriam ser discutidas em grupo, em sala de aula, com acompanhamento dos tutores, tornaram-se listas de exercícios semanais. Em geral, eram duas listas por semana com aproximadamente cinco exercícios cada, que deveriam ser entregues na sala de aula virtual da disciplina MA105 ao final da semana. Dessa forma, uma das atividades dos tutores tornou-se realizar a correção das listas dos integrantes de seu grupo de tutoria.

A disciplina organizou-se em ciclos semanais de atividades, com atribuições bem definidas aos diferentes atores (docente, calouros e tutores), conforme sintetizado na Tabela 1.

A turma de tutores foi dividida em duplas que deveriam redigir uma resolução comentada de cada uma das listas. As resoluções foram em geral textos bastante extensos (chegando a mais 
de 15 páginas), todos digitados, e com uma preocupação didática que se manifestou de diversos modos: ilustrações bem-feitas, exemplos diversos, apresentação de mais de um modo de solucionar os problemas, recordação ou apresentação de proposições relacionadas aos problemas, referências externas, memes etc.

Essas resoluções eram divulgadas logo após o prazo de entrega estipulado aos alunos, e foram efetivamente utilizadas pelos calouros como material de consulta (muitas vezes por indicação dos tutores), para rever algum conteúdo e entender os seus erros ou devido a algum eventual atraso na correção das listas entregues. Também foram utilizadas pelos demais colegas tutores, que se baseavam nesses textos para fazer as correções individuais dos alunos de seu grupo de tutoria.

A correção semanal dos exercícios, focada em comentários (em vez de notas), muitas vezes levava os calouros a se aprofundar em suas dúvidas e dificuldades, a partir das observações feitas pelo tutor. Em alguns casos, o tutor propunha uma lista adicional de exercícios, com foco nos principais problemas apresentados por aquele calouro na resolução das questões obrigatórias. Em algumas situações foram selecionadas questões que já estavam presentes na primeira lista, mas utilizando abordagem diferente, específica para o entendimento dos conceitos no qual o calouro enfrentava dificuldades. Como exemplo, em várias situações os tutores "quebraram" o problema proposto em itens menores, que conduziam à solução desejada, estratégia que se mostrou bastante proveitosa.

A correção individual dos exercícios foi um importante disparador na comunicação entre tutores e calouros. Podemos inferir que o retorno individual, chamando cada aluno pelo seu nome, foi percebido pelos tutorados como uma mensagem de que cada um deles, como indivíduo, era de fato importante para a turma. Após o término da disciplina, conversando com os tutores, nota-se a opinião quase que unânime de que não apenas esse tratamento foi importante para que os calouros se sentissem como parte da turma, mas também como forma de incentivá-los a conversar com seu tutor sobre suas dificuldades, tornando a relação muito mais pessoal, engajando-os na disciplina.

\subsubsection{Percepção de impacto}

Um ponto extremamente positivo a respeito da relação tutor-tutorado foi a proximidade que se estabeleceu entre as partes. É de se esperar que um aluno ingressante sinta-se mais à vontade para conversar e tirar dúvidas com colegas de curso do que com o docente, o que de certa forma pode ser justificado pela sensação de exposição ocasionada em uma situação de aula (remota ou não). O vínculo pessoal foi importante para que os tutores pudessem acompanhar o desenvolvimento dos calouros, no que diz respeito a sua aprendizagem e amadurecimento na disciplina e também no que se refere ao seu engajamento na universidade.

O elo estabelecido entre tutores e calouros, em muitos momentos, extrapolou as atividades das disciplinas, permitindo que os primeiros atuassem como "mentores" em questões relativas à universidade. Não foram poucos os casos em que ingressantes procuraram por seus colegas mais experientes para que fossem aconselhados sobre seu futuro na Unicamp, como qual seria o momento ideal durante o curso para realizar uma iniciação científica, quais métodos de estudos mostravam-se mais adequados para determinada disciplina ou até mesmo em busca de incentivos para que não desistissem da universidade em meio ao ensino remoto (receio compartilhado por diversos docentes do curso em reuniões de discussão sobre o início do período remoto).

Os tutores tiveram um papel essencial em manter os calouros engajados e motivados, a despeito das dificuldades do ensino remoto: o temor inicial de evasão em massa do curso dos calouros (que não chegaram a experimentar in-loco a vivência universitária) não se concretizou. Podemos avaliar isso 
pelo número de estudantes que chegaram a concluir a disciplina (no sentido de chegar a participar da última avaliação), que foi similar (um pouco superior) ao de anos anteriores.

\subsubsection{Atividades formativas para tutores}

Nesta seção discutimos a contribuição das atividades de tutoria para a formação dos tutores, alunos da disciplina Currículo e Didática da Matemática, todos nos semestres finais de seus cursos. As contribuições aqui elencadas partem da experiência da quarta autora (que atuou como tutora), de sua vivência com os colegas de turma e também de diversos pontos destacados pelos tutores em seus relatórios finais.

A primeira contribuição à formação dos tutores refere-se a responsabilidade e compromisso. Como dito por alguns tutores, um dos aspectos mais importantes da disciplina foi sentirem-se responsáveis e comprometidos com a aprendizagem dos calouros, muitos vivenciando pela primeira vez este que é um compromisso central da vida profissional de um professor.

A correção das listas de exercícios, feita semanalmente, também trouxe contribuições significativas à formação dos tutores. Além de registrar a entrega (para efeito de nota na disciplina), os tutores precisaram antes de tudo perceber o que de fato os alunos estavam entendendo, qual a origem de seus erros e vislumbrar caminhos para orientá-los e auxiliá-los, o que ultrapassa em muito a complexidade de simplesmente "corrigir e dar nota".

De fato, revendo, após a conclusão da disciplina os comentários feitos pelos tutores, é nítida a diferença entre os comentários inciais (muitas vezes uma "correção" breve com indicação de resposta ou caminho correto) e os comentários no final do semestre, muito mais longos, sugerindo alternativas, fazendo perguntas e também mais pessoais, falando ao aluno e não apenas reagindo ao documento. Nesse sentido, a tutoria fomentou a percepção (e alguma compreensão, não sistemática) por parte dos tutores do entendimento dos alunos, um embrião de uma aprendizagem que é um dos principais tipos específicos de Conhecimento Pedagógico de Conteúdos (PCK, na sigla em inglês), conforme destacado, por exemplo, em [4]. A visão retrospectiva das "correções" também permite perceber o desenvolvimento de sua capacidade de entender os erros dos alunos, uma habilidade reconhecida como importante na literatura sobre erros em ensino de matemática (ver, por exemplo, [2]).

Uma contribuição significativa, específica deste período de ensino remoto, foi o domínio dos recursos do Google Sala de Aula (adotado por muitas escolas durante o ensino remoto, em particular pela rede estadual de São Paulo), assim como recursos para comentar soluções e se comunicar remotamente, por meio de textos, áudios e vídeos.

Para finalizar, a redação das resoluções comentadas dos exercícios mostrou-se uma atividade bastante significativa para a formação dos tutores. Além do aprendizado sobre o uso de LaTeX, para grande parte da turma escrever matematicamente as soluções foi um exercício novo e desafiador, pois era preciso que os textos e as passagens utilizadas para cada resolução fossem compreensíveis para os calouros, buscando antecipar suas dificuldades, apresentar soluções alternativas ou animar e motivar os tutorados. Como pode ser visto em https://www.ime.unicamp.br/ barichello/pmo/ ma105.html, na maioria das vezes os textos iam muito além de tradicionais "gabaritos", tendo muitas características da definição ampla de transposição didática adotada em [7]. 


\subsection{Parceria entre docente e tutores: correções de rumo}

É relevante destacar que ao longo do semestre houve uma parceria efetiva entre o docente responsável e os tutores. Nos encontros semanais, diversos aspectos relativos à organização da disciplina eram discutidos, sempre buscando um entendimento conceitual de subordinação das estratégias aos objetivos da disciplina. Ao longo do semestre, essas discussões acarretaram uma série de mudanças e correções de rumo, dentre as quais destacamos:

- Mudança de prazos de entrega de atividades, que estava previsto para ocorrer a cada aula e passou a ocorrer apenas uma vez por semana.

- Exercícios individuais foram muitas vezes substituídos por outras atividades propostas pelos tutores.

- As listas de exercícios passaram a ser divididas em duas sessões: exercícios básicos e desafios. A escolha de qual parte resolver ficava a critério dos alunos, muitas vezes aceitando recomendações dos tutores.

- No que se refere ao prazo de correção dos exercícios, os tutores passaram a ter mais flexibilidade, levando em consideração tanto as necessidades e interesses dos alunos, como a própria disposição de tempo.

Esse tipo de parceria entre docentes e estudantes não é comum nas disciplinas de matemática da Unicamp. Na pandemia mostrou-se especialmente valiosa.

\section{Considerações Finais}

O objetivo deste texto era relatar como foram as experiências com duas disciplinas de perfil bastante diferente oferecidas para ingressantes de Licenciatura em Matemática na Unicamp, a primeira delas Seminário sobre Ensino de Matemática, e a segunda, Matemática Elementar, sendo que essa é oferecida de forma combinada com uma disciplina cursada por estudantes veteranos do mesmo curso que atuam como tutores dos ingressantes.

Ambas as disciplinas, assim como a maioria das disciplinas oferecidas na Unicamp, foram prontamente adaptadas para o ensino remoto emergencial, e o relato buscou evidenciar como isso foi realizado em cada uma delas.

No caso de Seminários de Ensino de Matemática, o formato original da disciplina baseado em palestras independentes foi abandonado e adotou-se um conjunto de atividades semanais que foram efetivadas no formato online através de um conjunto de itens multimídia variados, possibilitando diferentes formas de interação com os estudantes e uma experiência que se aproximou, em vários sentidos, de uma sala de aula invertida.

No caso de Matemática Elementar, as interações presenciais que se concretizariam originalmente em horários para resolução de problemas por parte dos ingressantes sob tutoria dos veteranos foram substituídas por interações virtuais entre os tutores e seus grupos, correção com sugestões personalizadas, enquanto o docente responsável assumiu o componente mais expositivo da disciplina e a orientação do trabalho dos tutores.

Do ponto de vista institucional, além das aprendizagens acerca do formato remoto, ambas as experiências foram também fundamentais para a solidificação das duas disciplinas dentro do currículo 
da Licenciatura em Matemática da Unicamp. Enquanto pode-se dizer que a disciplina Seminários sobre Ensino de Matemática teve uma mudança no seu caráter, que mudou de palestras avulsas para conjuntos de atividade independentes, o sistema de "estágio interno" e tutoria criado pela combinação das disciplinas Matemática Elementar e Currículo e Didática da Matemática, por ter sido incorporada recentemente ao currículo desse curso, ainda está em processo de amadurecimento. Dessa forma, apesar do caráter de exceção forçado pela pandemia, acreditamos que as experiências relatadas neste texto deixarão marcas em ambas as disciplinas nos próximos semestres, independentemente da natureza das interações possíveis.

\section{Referências}

[1] BARICHELLO, L. "Estudos matemáticos" e uma chamada para uma pesquisa coletiva". Revista do Professor de Matemática, v. 100, pp. 3-5, 2019.

[2] BORASI, R. Capitalizing on errors as"springboards for inquiry: A teaching experiment. Journal for research in mathematics education, 166-208, 1994.

[3] DI MARTINO, P.; MELLONE, M.; RIBEIRO, M. "Interpretative Knowledge". In: LERMAN, S. (Ed.). Encyclopedia of Mathematics Education. Cham: Springer International Publishing, p. $1-5,2019$.

[4] GRAEBER, A.'Forms of Knowing Mathematics: What Preservice Teachers Should Learn", Educational Studies in Mathematics, v. 38, n. 1-3, pp. 189-208, 1999.

[5] HOOvER, M., Mosvold, R., Ball, D., Lai, Y. "Making Progress on Mathematical Knowledge for Teaching". ztextitThe Mathematics Enthusiast, v. 13, n. 1, p. 33, 2016.

[6] JONES, I. et al. "Measuring conceptual understanding: The case of fractions. Proceedings of the 37th Conference of the International Group for the Psychology of Mathematics Education. Anais".In: International group for the psychology of mathematics education. Kiel, Germany: 2013

[7] KANG, Wan; KILPATRICK, Jeremy. "Didactic transposition in mathematics textbooks". For the Learning of Mathematics, v. 12, n. 1, p. 2-7, 1992.

[8] SCHILlinG, S. G.; HILL, H. C. "Assessing Measures of Mathematical Knowledge for Teaching: A Validity Argument Approach". Measurement: Interdisciplinary Research and Perspectives, v. 5, n. 2-3, p. 70-80, 1 ago. 2007.

[9] SHULMAN, L. S. "Those who understand: Knowledge growth in teaching". Educational researcher, v. 15, n. 2, p. 4-14, 1986.

[10] SILVA, M. R. P. D.; Oliveira, S. R. "Um quebra-cabeças aberto para a demonstração do Teorema Fundamental do Cálculo". In: Anais do IX Seminário Interno do PECIM. 2019. 
Leonardo Barichello Universidade Estadual de Campinas <barichello@ime.unicamp.br>

Marcelo Firer Universidade Estadual de Campinas <mfirer@unicamp.br>

Rita Santos Guimarães Universidade Estadual de Campinas <guimaraes.rita@gmail.com>

Letícia Fernandes Soriani Universidade Estadual de Campinas $<$ lefernandes.soriani@gmail.com>

Recebido: $15 / 10 / 2020$

Publicado: 02/02/2021

Chamada Temática "Experiências didáticas em Matemática no período de isolamento social" 